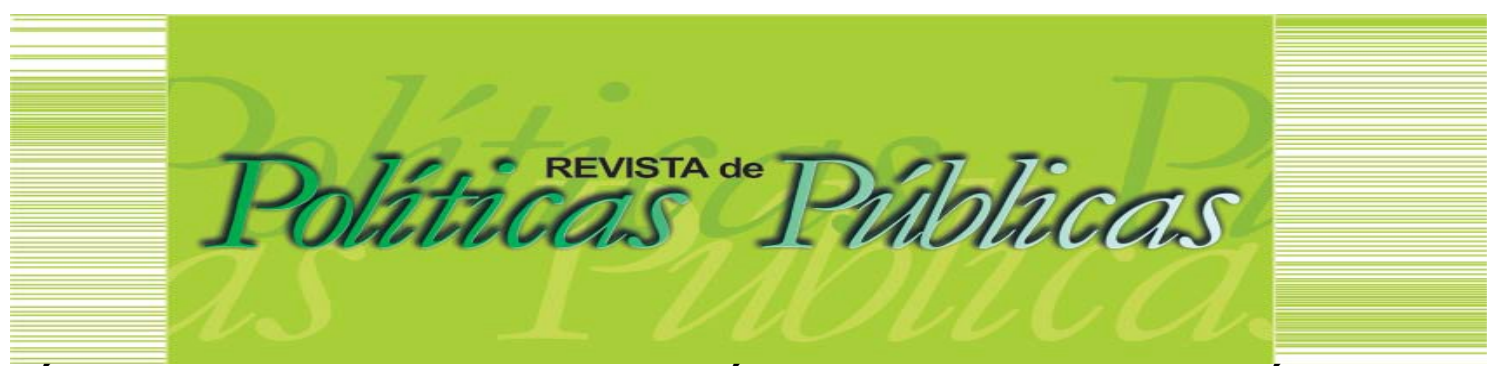

\title{
ÁREAS DE AFLORAMENTO DO AQUÍFERO GUARANI (SP) E POLÍTICAS DE RECURSOS HÍDRICOS: medidas para gestão
}

\author{
Flavia Darre Barbosa ${ }^{1}$ \\ Anayra Giacomelli Lamas Alcantara² \\ Luiz Eduardo Moschini3 \\ Érica Pugliesi ${ }^{4}$ \\ Mauricio José Rosso Pinto 5 \\ Frederico Yuri Hanai ${ }^{6}$
}

\section{Resumo}

O estudo procurou entender como é tratada a questão das águas subterrâneas, sobretudo das áreas de afloramento do Sistema Aquífero Guarani no estado de São Paulo nas Unidades de Gerenciamento de Recursos Hídricos Pardo e Tietê/Jacaré, em relação às Legislações de Recursos Hídricos nacional e estadual, e de que forma estas áreas são consideradas na gestão destas unidades. Para tanto, realizou uma revisão bibliográfica a respeito das leis brasileiras e paulistas de recursos hídricos, e pesquisa documental no portal do Sistema de Informação e Gerenciamento de Recursos Hídricos. Como principal resultado, foi possível verificar que as águas subterrâneas, principalmente na área de afloramento do SAG, ainda são abordadas de forma superficial, não havendo as garantias necessárias para que a gestão integrada e descentralizada dos recursos hídricos ocorra de maneira efetiva.

Palavras-chave: Água subterrânea. Aquífero guarani. Políticas de recursos hídricos. Área de afloramento. Unidades de Gerenciamento de Recursos Hídricos do Estado de São Paulo.

\section{OUTCROPS AREAS OF THE GUARANI AQUIFER (SP) AND WATER RESOURCES POLICIES: measures for management}

\section{Abstract}

1 Cientista social. Geógrafa. Doutoranda do Departamento de Ciências Ambientais. Programa de Pós-Graduação em Ciências Ambientais da Universidade Federal de São Carlos. Mestra em Geografia pela Universidade Estadual Paulista (UNESP); Doutora em Ciências Ambientais pela Universidade Federal de São Carlos (UFSCAR). Vínculo Empregatício:Professora de Geografia na rede Objetivo de Ensino- Ensino Médio e Fundamental; Prestadora de Serviços editorias para Pearson- revisora de materiais didáticos na área de Geografia. Email: flavia_darre@yahoo.com.br.

2 Bióloga. Prestadora de serviços editoriais para a elaboração de materiais didáticos de ciências e biologia (autônoma). Mestranda no Programa de Pós Graduação em Ciências Ambientais. Universidade Federal de São Carlos. Email: anayra.bio@gmail.com

3 Professor Doutor titular no Departamento de Ciências Ambientais da Universidade Federal de São Carlos.

${ }^{4}$ Farmacêutica-Biquímica. Professora Doutora titular no Departamento de Ciências Ambientais da Universidade Federal de São Carlos e docente do Programa de Pós-Graduação em Ciências Ambientais (PPGCAm) da UFSCar. Endereço: Rodovia Washington Luiz, km 235 - SP-310, São Carlos - SP, 13565-905.E-mail: epugliesi@ufscar.br.

5 Engenheiro ambiental. Mestre em Ciências Ambientais pela Universidade Federal de São Carlos (UFSCAR). Coordenador ambiental de projetos na Universidade de Córdoba (Colômbia) e consultor ambiental autônomo. Email: mirossop@gmail.com.

6 Engenheiro. Doutor em Ciências da Engenharia Ambiental (Universidade de São Paulo - USP). Professor do Departamento de Ciências Ambientais (DCAm) da Universidade Federal de São Carlos (UFSCar), docente no Curso de Bacharelado em Gestão e Análise Ambiental e orientador credenciado no Programa de Pós-graduação em Ciências Ambientais (PPGCAm). Endereço: Rodovia Washington Luiz, km 235 - São Carlos - SP - CEP 13.565-905. E-mail: fredyuri@ufscar.br. 
ÁREAS DE AFLORAMENTO DO AQUÍFERO GUARANI (SP) E POLÍTICAS DE RECURSOS HÍDRICOS: medidas para gestão

The research sought to understand how the Water Resources Legislation addresses the management of outcrop areas of the Guarani Aquifer System in the state of São Paulo, specifically in the Pardo and Tietê/Jacaré Water Resources Management Units. Therefore, a bibliographical review was carried out regarding the Brazilian and São Paulo laws of water resources, as well as a documentary research in the portal of the System of Information and Management of Water Resources. As a main result it was possible to verify that groundwater, mainly in the outcrop area of the SAG, is still superficially addressed, and there is no guarantee that the integrated and decentralized management of water resources will be effectible apply.

Keywords: Groundwater. Guarani aquifer. Water resources policies. Outcrops. Water Resources Management Units (UGRHIS) of the State of São Paulo.

Artigo recebido em: 18/08/2019 Aprovado em: 27/01/2020 DOI: http://dx.doi.org/10.18764/2178-2865.v24n1p87-107. 


\section{INTRODUÇÃO}

As águas subterrâneas são consideradas uma das principais fontes de água doce disponível para o consumo da humanidade, já que $98 \%$ das reservas de água doce e líquida estão armazenadas em aquíferos e, num contexto de mudanças climáticas globais, apresentam grande potencial devido à sua resistência em longos períodos de estiagem (HIRATA; ZOBY; OLIVEIRA, 2010; VILLAR, 2012).

Segundo Rebouças (2006), a água subterrânea é utilizada pelo ser humano há milhares de anos e representa muitas vantagens em relação à água de superfície. Na ausência de fontes poluidoras, poderíamos consumi-la diretamente após a sua captação, devido aos processos naturais de autodepuração que ocorrem no subsolo (BRASIL, 2007; CPTI, 2008a). Mesmo assim, as águas subterrâneas são amplamente desconhecidas e esquecidas, sendo muitas vezes desconsideradas dos processos de gestão, ou tratadas e geridas como recurso de categoria secundária quando comparadas às águas de superfície (CPTI, 2008a; HIRATA; ZOBY; OLIVEIRA, 2010; VILLAR, 2012).

O grande e crescente uso indiscriminado da água subterrânea para abastecimento humano, bem como os progressivos processos de contaminação da água armazenada nos aquíferos, justifica a preocupação que se deve ter com a gestão destas águas em relação aos usos e à qualidade e quantidade.

Diversos municípios brasileiros de grande, médio e pequeno porte, considerando a densidade demográfica, são parcial ou totalmente abastecidos por águas de aquíferos (HIRATA; ZOBY; OLIVEIRA, 2010), sendo em muitos casos o principal manancial hídrico (BRASIL, 2006). Segundo levantamento realizado para a elaboração do Plano Nacional de Recursos Hídricos, 15,6\% dos domicílios utilizam exclusivamente água subterrânea (BRASIL, 2006).

O estado de São Paulo atualmente é o maior usuário de águas subterrâneas no país. Cerca de $80 \%$ dos municípios paulistas são abastecidos - mesmo que parcialmente - por águas subterrâneas, atendendo uma população de mais de 5,5 milhões habitantes (SÃO PAULO, 2010; 2016) e destes, aproximadamente "47,7\% são municípios totalmente abastecidos por este recurso hídrico" (VILLAR, 2010, p.7). Conforme aponta Villar (2010), são exemplos desta situação cidades como Ribeirão Preto, Matão, Sertãozinho, Andradina, Cajamar e Lins.

No contexto das águas subterrâneas, o Sistema Aquífero Guarani (SAG) destaca-se dentre os principais reservatórios de água subterrânea do mundo. Trata-se de um extenso conjunto de estratos rochosos com características aquíferas, presente no subsolo de quatro países da América Latina: Brasil, Argentina, Paraguai e Uruguai, totalizando uma área de 1.087 .879 Km² (OEA, 2009), 
sendo que a maior porção está situada em território brasileiro, englobando os estados de Goiás, Mato Grosso, Mato Grosso do Sul, Minas Gerais, São Paulo, Paraná, Santa Catarina e Rio Grande do Sul.

O SAG é composto por rochas sedimentares de arenitos, que armazenam água em seus poros e fendas, e confinamento basáltico e está geomorfologicamente estruturado em duas áreas de recarga. Suas rochas arenosas pertencem às formações triássicas e jurássicas da Bacia Sedimentar do Paraná, respectivamente, formações Pirambóia e Botucatu na porção brasileira (RABELO, 2006).

O processo de recarga direta do aquífero ocorre em sua porção aflorante, ou seja, que se encontra na superfície do terreno e que se comporta como aquífero livre, e corresponde a apenas 10\% de sua área total, aproximadamente (IRITANI; EZAKI, 2009), sendo esta a porção mais vulnerável à contaminação do aquífero por conta do uso e ocupação inadequado do solo (SÃO PAULO, 2013; IPT, 2011). As demais áreas em que ocorre a recarga indireta equivalem a 90\% das rochas sedimentares que estão confinadas por basalto. A recarga indireta corresponde ao fluxo descendente de água por meio das falhas e fissuras do basalto (RABELO, 2006).

Desse modo, as áreas de afloramento, são imprescindíveis para a qualidade das águas subterrâneas e para a sustentabilidade das reservas (BRASIL, 2007). Logo, a proteção e a gestão das áreas de recarga são medidas necessárias e emergenciais, tendo em vista as inúmeras atividades antrópicas que, segundo Brasil (2007) e Rabelo (2006), interferem na permeabilidade do solo e em suas taxas de recarga.

Nesse contexto, o estado de São Paulo é estratégico no tocante à realização de estudos e ações para a conservação do SAG. Este estado possui importantes áreas de afloramento do SAG, tanto em extensão das áreas quanto pelas atividades econômicas que se desenvolvem nessas regiões (ALBUQUERQUE FILHO et al., 2010).

A área de afloramento do SAG no estado de São Paulo está localizada na porção central. Estende-se desde 0 município de Rifaina, a norte, até Fartura, ao sudoeste (DAEE, 2005). Esta extensão territorial possui uma área de 23.500 km² (ALBUQUERQUE FILHO et al., 2010) e está inserida na faixa de transição entre os geossistemas da Depressão Periférica e o Planalto Ocidental Paulista, apresentando largura irregular, que se amplia ao longo das grandes drenagens (DAEE, 2005).

Ocorre em 07 das 22 Unidades de Gerenciamento de Recursos Hídricos- UGRHIs (DAEE, 2005; ALBUQUERQUE FILHO et al., 2010; SEMA, IG/DATAGEO, 2007), conforme apresentado na Figura 1. 
Figura 1 - Área de Afloramento do SAG em relação às UGRHIs do estado de São Paulo

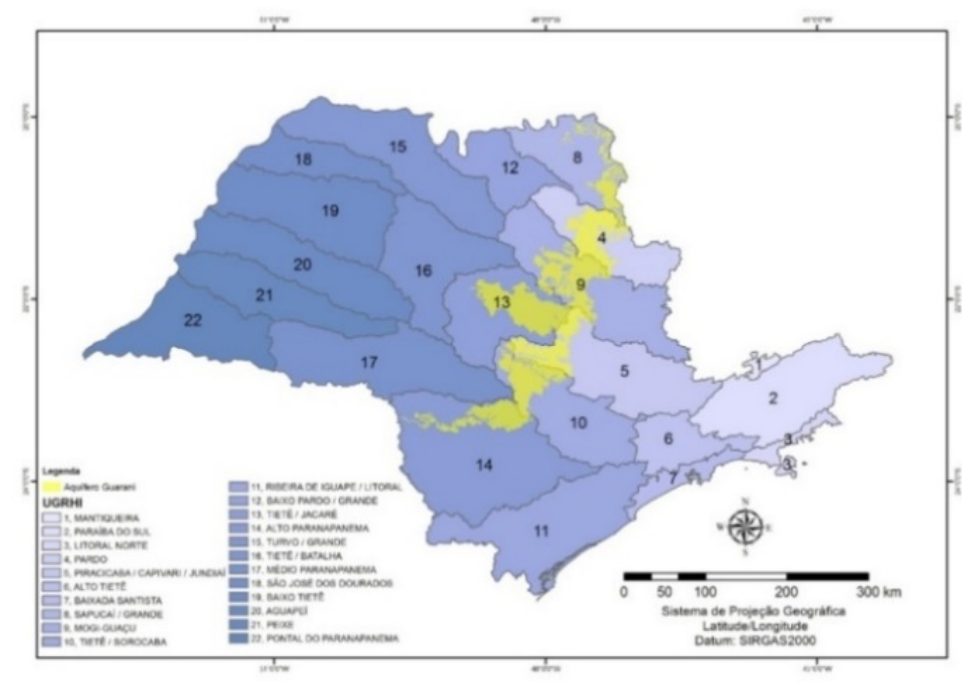

Fonte: Elaborado pelos autores, 2017.

As UGRHIs que estão na área de afloramento do SAG são a UGRHI 04 - Pardo, UGRHI 05 - Piracicaba/Capivari/Jundiaí, UGRHI 08 - Sapucaí Mirim/Grande, UGRHI 09 - Mogi Guaçu, UGRHI 10 - Tietê Sorocaba, UGRHI 13 - Tietê Jacaré, UGRHI 14 - Alto Paranapanema, UGRHI 16 TietêBatalha e UGRHI 17 Médio Paranapanema (SÃO PAULO, IPT, 2011). Cada uma das UGRHIs do estado de São Paulo é gerenciada por um Comitê de Bacia, que é responsável por aprovar o Plano de Bacia Hidrográfica e viabiliza a gestão dos recursos hídricos no estado.

A porcentagem do território das UGRHIs que são ocupadas pela área de afloramento é desigual. A UGRHI 04 - Pardo e a UGRHI 13 - Tietê - Jacaré são as que possuem maior extensão territorial ocupada pela área de afloramento, (SÃO PAULO, 2011) conforme apresenta a tabela 1. As UGRHIs 04 e 13 também possuem, em relação às outras UGRHIs, a maior porcentagem de municípios que tem seu território inserido na área de afloramento.

Tabela 1- Municípios paulista e área da UGRHI ocupada do SAG

\begin{tabular}{|cccc}
\hline UGRHIs & $\begin{array}{c}\text { Total de Municípios } \\
\text { nas UGRHI's }\end{array}$ & $\begin{array}{c}\text { Municípios que possuem território na área } \\
\text { de afloramento do SAG }\end{array}$ & $\begin{array}{c}(\%) \text { da área de } \\
\text { UGRHI no SAG }\end{array}$ \\
\hline $\begin{array}{c}04 \text { - Pardo } \\
05-\text { PCJ }\end{array}$ & 27 & 16 & $39,00 \%$ \\
\hline $\begin{array}{c}08 \text { - Sapucaí Mirim/ } \\
\text { Grande }\end{array}$ & 61 & 11 & $21,10 \%$ \\
\hline 09 - Mogi Guaçu & 23 & 14 & $36,80 \%$ \\
\hline 10 - Tietê Sorocaba & 43 & 14 & $29,80 \%$ \\
\hline 13 - Tietê - Jacaré & 34 & 10 & $27,70 \%$ \\
\hline 14 - Alto Paranapanema & 34 & 25 & $39,70 \%$ \\
\hline
\end{tabular}




\begin{tabular}{cccc}
16 - Tietê Batalha & 36 & 1 & $0,10 \%$ \\
17 - Médio Paranapanema & 45 & 2 & $0,40 \%$ \\
\hline
\end{tabular}

Elaborado por autores, 2017. Fonte: Adaptado de SÃO PAULO, IPT, 2011.

Conforme dados de indicadores produzidos pelo DAEE (2005), a dependência das UGRHIs Pardo e Tietê Jacaré para o uso das águas subterrâneas para abastecimento público é alta, estando acima de $50 \%$ de população abastecida. (DAEE, 2005).

Com relação à demanda total de águas subterrâneas que considera também os usos agrícolas e industriais, estas duas UGRHIs também possuem a maior demanda em relação a todas as outras da área de afloramento (DAEE, 2005). A tabela 2 apresenta a relação de dependência das UGRHIs da área de afloramento conforme os indicadores utilizados pelo DAEE (2005).

Tabela 2 - Relação da Dependência das UGRHIs da área de afloramento do SAG com relação ao abastecimento público e demanda total de água subterrânea

\begin{tabular}{lcc} 
UGRHls & Abastecimento Público (\%) & Demanda total Usos Múltiplos (\%) \\
\hline 04 - Pardo & 69 & 20 \\
\hline 05 - PCJ & 5 & 2 \\
08 - Sapucaí - Mirim/ Grande & 28 & 7 \\
\hline 09 - Mogi Guaçu & 25 & 10 \\
10 - Tietê Sorocaba & 12 & 6 \\
13 - Tietê - Jacaré & 61 & 29 \\
14 - Alto Paranapanema & 8 & 5 \\
16 - Tietê Batalha & 91 & 11 \\
17 - Médio Paranapanema & 44 & 26 \\
\hline
\end{tabular}

Elaborado por autores, 2017. Fonte: Adaptado de DAEE, 2005.

Diante da importância que estas áreas de afloramento possuem para 0 bom funcionamento de todo o SAG, este trabalho teve como objetivo investigar a evolução histórica da legislação e normativas sobre águas subterrâneas paulistas e brasileiras, e analisar a gestão das UGRHIs 04 e 13 na gestão das áreas de afloramento do SAG no estado de São Paulo, uma vez que se destacam em relação às outras, conforme os dados anteriormente apresentados. Buscou-se responder às seguintes questões: (1) Como é tratada a questão das águas subterrâneas nas Legislações de Recursos Hídricos brasileira e paulista? (2) Do que trata a legislação específica para as águas subterrâneas no estado de São Paulo? (3) As áreas de afloramento do SAG estão sendo consideradas para a gestão das UGRHIs 04 e 13? Como?

Este estudo foi realizado por meio de revisão bibliográfica relacionada às Leis brasileira e paulista para a gestão de recursos hídricos, bem como outras referências da área, complementando com a pesquisa documental realizadas no portal do Sistema de Informação e Gerenciamento de 
Recursos Hídricos do Estado de São Paulo - SIGRH. As informações relacionadas às áreas de afloramento do Sistema Aquífero Guarani, no estado de São Paulo, permitiram a construção da contextualização do problema e a compreensão dos dados para a concepção do referencial teórico da pesquisa e a análise da situação atual e as medidas de gestão possíveis.

Nesta pesquisa os principais documentos analisados foram os Planos de Bacia e o último Relatório de Situação das UGRHIs em questão. Além disso, foi utilizado o Sistema de Informação Geográfica (SIG) - com Software ArcGis, para a confecção do mapa para delimitação da área de afloramento no estado de São Paulo e os mapas dos municípios de cada UGRHI, que estão na área de afloramento. Esses mapas foram elaborados a partir dos dados disponibilizados no site DATAGEO em formato shape.

\section{A ÁGUA SUBTERRÂNEA NA LEGISLAÇÃO DE RECURSOS HíDRICOS BRASILEIRA E PAULISTA}

Em 1934 foi sancionada a primeira legislação que estabelece as diretrizes e critérios para a utilização dos recursos hídricos no Brasil, o Código das Águas. Nesta legislação as águas subterrâneas eram consideradas de domínio privado, podendo ser exploradas pelo dono do terreno desde que a exploração não prejudicasse o uso comum ou interferisse nas águas públicas, sendo o controle para o uso e proteção realizado pelo poder público (REBOUÇAS, 2002).

Segundo Rebouças (2002), em 1967 o Código da Mineração coloca as águas subterrâneas como uma das classificações das jazidas minerais, e estabelece que estas serão regidas por leis especiais, criando o ambiente necessário para a elaboração de uma legislação específica para proteção qualitativa e quantitativa das águas subterrâneas, culminando no projeto de Lei no 7.127/86, arquivado após a criação do Ministério do Meio Ambiente em 1995.

Entre o Código das Águas de 1934 e o arquivamento do projeto de lei para águas subterrâneas em 1995, a Constituição Federal de 1988 modifica o domínio das águas subterrâneas, que passam a pertencer aos Estados. A competência para legislar sobre as águas passa a ser de responsabilidade da União, que também deve articular as ações dos Estados.

O primeiro estado a estabelecer uma legislação específica para a gestão dos recursos hídricos foi o estado de São Paulo, a Lei n 7.633 que estabeleceu a Política Estadual de Recursos Hídricos (PERH) no ano de 1991. A PERH estabelece, em seus princípios, que a gestão deva ser descentralizada, integrada e participativa sem a dissociação dos aspectos quantitativos e qualitativos e das fases meteórica, superficial e subterrânea do ciclo hidrológico (SÃO PAULO, 1991a).

Em suas diretrizes, a PERH prevê a utilização racional das águas subterrâneas, com desenvolvimento de programas permanentes de conservação e proteção contra poluição e 
superexploração, estando sujeito a outorga e cadastramento qualquer empreendimento que utilize estas águas no abastecimento humano, industrial e agrícola, e lançamento de efluentes, cabendo ao DAEE- Departamento de Águas e Energia Elétrica de São Paulo o licenciamento e outorga destas águas (SÃO PAULO, 1991a).

O Capítulo II da Lei $n^{0} 7.633$ refere-se aos diversos tipos de participação na gestão dos recursos hídricos, dedicando uma especial atenção à inserção dos municípios na gestão de águas subterrâneas. O Artigo $32^{\circ}$ da Lei supracitada estabelece que o Estado poderá delegar aos Municípios que se organizarem técnica e administrativamente, o gerenciamento de recursos hídricos de interesse exclusivamente local, compreendendo, dentre outros, os de bacias hidrográficas que se situem exclusivamente no território do Município e os aquíferos subterrâneos situados em áreas urbanizadas (SÃO PAULO, 1991a).

Ademais, as águas subterrâneas são citadas na Lei $n^{0} 7.633$, pois, uma fração dos recursos do Fundo Estadual de Recursos Hídricos (FEHIDRO) deverá ser constituída por parte da compensação financeira que o Estado receber pela aplicação exclusiva em levantamentos, estudos e programas de interesse para o gerenciamento dos recursos hídricos subterrâneos, entre outros. (SÃO PAULO, 1991a. Artigo 36. Inciso IV).

Conforme a PERH, um dos instrumentos principais de gestão dos recursos hídricos é 0 Plano Estadual de Recursos Hídricos. Neste documento, com abrangência para os anos de 2012-2015, as águas subterrâneas aparecem primeiramente no conteúdo diagnóstico, que apresenta de forma geral as principais características dos aquíferos do estado. Posteriormente o Plano trata das demandas de águas subterrâneas outorgadas e disponibilidade, sendo que a exploração destas reservas tem apresentado aumento gradativo. Nesta perspectiva, o SAG possui maior produtividade para a disponibilidade, e tem elevado potencial de vazão por poço.

O documento destaca que a área de afloramento do SAG possui alta vulnerabilidade em relação às dinâmicas urbanas e rurais como poluição difusa, vazamentos do sistema de esgotamento sanitário, indicando o cuidado para futuras instalações e ocupações (SÃO PAULO, 2013). A qualidade das águas subterrâneas também é retratada no Plano e as ações propostas para essas águas são: 0 cadastramento e regularização da outorga de poços, o desenvolvimento de instrumentos normativos de proteção da qualidade das águas subterrâneas e o acompanhamento e controle da perfuração de poços para evitar a superexplotação destas águas.

Antes de ser aprovada a PERH, em 1991, o estado de São Paulo foi o precursor na formulação de uma lei específica para águas subterrâneas, a Lei $n^{\circ} 6.134$, de 1988 , que foi elaborada até mesmo antes da promulgação da Constituição Federal. A lei foi regulamentada em 1991 pelo Decreto $n^{\circ} 32.955$, e dispõe sobre a preservação dos depósitos naturais de águas subterrâneas do 
Estado de São Paulo e estabelece, entre outros dispositivos, a necessidade de elaboração de programas permanentes de conservação e a obrigatoriedade de cadastramento de todo poço que é perfurado (FIESP, 2005), sendo "sempre levadas em conta a interconexão entre as águas subterrâneas e superficiais e as interações observadas no ciclo hidrológico" (SÃO PAULO, 1988, Artigo $\left.2^{\circ}\right)$.

O Decreto estabelece ainda três áreas de proteção sendo (1) Área de Proteção Máxima, (2) Área de Restrição e Controle e (3) Área de Proteção de Poços e Outras Captações, restringindo e permitindo diversos tipos de utilização destas águas para cada situação (SÃO PAULO, 1991b).

Convém ressaltar para este trabalho as especificações da Área de Proteção Máxima, que compreendem, "no todo ou em parte, as zonas de recarga de aquíferos altamente vulneráveis a poluição e que se constituíam em depósitos de águas essenciais para abastecimento público" (SÃO PAULO, 1991b, Artigo $20^{\circ}$, Inciso I). Nestas áreas, em que estão incluídas áreas de afloramento por questão conceitual, não serão permitidas:

\footnotetext{
I - a implantação de indústrias de alto risco ambiental, polos petroquímicos, carboquímicos e cloroquímicos, usinas nucleares e quaisquer outras fontes de grande impacto ambiental ou de extrema periculosidade;

II - as atividades agrícolas que utilizem produtos tóxicos de grande mobilidade e que possam colocar em risco as águas subterrâneas, conforme relação divulgada pela CETESB Companhia de Tecnologia de Saneamento Ambiental e Secretaria de Agricultura e Abastecimento;

III - o parcelamento do solo urbano sem sistema adequado de tratamento de efluente ou de disposição de resíduos sólidos (SÃO PAULO, 1991b, Artigo 21).
}

Outra política pública de relevante interesse para o tema é a Lei de Proteção de Mananciais do Estado de São Paulo, de 1997, n 9.866. Esta lei "estabelece diretrizes e normas para a proteção e a recuperação da qualidade ambiental das bacias hidrográficas e dos mananciais de interesse regional" (SÃO PAULO, 1997, Artigo $1^{\circ}$ ). Entre os mananciais de interesse regional estão as águas interiores subterrâneas.

A referida Lei também define as prioridades e diretrizes para a criação de Áreas de Proteção e Recuperação de Mananciais, APRMs, que serão definidas e delimitadas em propostas realizadas pelos Comitês de Bacia Hidrográfica e posteriormente por deliberação do Conselho Estadual de Recursos Hídricos, devendo estar inseridas territorialmente nas UGRHIs (SÃO PAULO, 1997).

Essa lei estabelece três instrumentos importantes para as APRMs: o estabelecimento de leis específicas; a formulação do Plano de Desenvolvimento e Proteção Ambiental (PDPA); e o estabelecimento de orientações e mecanismos de fiscalização, compensação e aplicação de penalidades, e, para cada APRM, indica que deverá ser criada outra legislação específica (SÃO PAULO, 2011). 
As APRMs deverão ser compartimentadas em três áreas de intervenção: áreas de restrição à ocupação; área de ocupação dirigida; e áreas de recuperação ambiental. É possível inferir que as APRMs deverão estar bem caracterizadas e já delimitadas nos Planos de Bacia Hidrográfica, que é o principal instrumento de gestão dos Comitês de Bacia, sobretudo para estes contribuírem na elaboração do PDPA.

Em 2011 foi elaborado pelo governo do estado de São Paulo um documento com diretrizes para subsidiar o PDPA e, consequentemente, a criação da APRM-SAG. Um dos desafios apontados neste documento, para a gestão da APRM-SAG é articular ações de âmbito regional, de responsabilidade do Estado e dos Comitês de Bacia, com as ações de âmbito local, que são de responsabilidade dos municípios (SÃO PAULO, 2011). Passados sete anos da publicação do documento supracitado, a Lei para a criação da APRM-SAG ainda configura como Minuta.

No âmbito da Política Nacional de Recursos Hídricos (PNRH) de 1997, o primeiro marco para a integração das águas subterrâneas e águas superficiais ocorreram com a aprovação pelo Conselho Nacional de Recursos Hídricos (CNRH), da Resolução n. ${ }^{\circ}$ 15/2001, que estabelece diretrizes para gestão integrada das águas e da Resolução n 22/2002, que contempla diretrizes para a inserção dos estudos sobre águas subterrâneas nos Planos de Recursos Hídricos. Estas medidas trazem à tona a temática dos múltiplos usos dessas águas, as peculiaridades dos aquíferos e os aspectos relacionados à sua qualidade e quantidade (SENRA et al., 2012).

$\mathrm{Na} \mathrm{PNRH}$, especificamente, os temas águas subterrâneas e aquíferos aparecem primeiramente relacionados ao instrumento de outorga. Este instrumento tem como objetivos assegurar o controle quantitativo e qualitativo dos usos da água e o efetivo exercício dos direitos de acesso à água (BRASIL, 1997), e tem a função de conceder a autorização para o uso da água.

Na seção III da PNRH, o parágrafo II do Artigo $12^{\circ}$ refere-se especificamente à outorga para extração de água de aquífero subterrâneo para consumo final ou insumo de processo produtivo. Até então não havia sido mencionada a água subterrânea ou aquífero na referida lei. Posteriormente, a água subterrânea é citada na lei federal quando esta estabelece as infrações e penalidades para a utilização dos recursos hídricos superficiais e subterrâneos. No Título III, Artigo $49^{\circ}$, os parágrafos I e V referem-se às águas subterrâneas da seguinte forma, sendo infração

II - iniciar a implantação ou implantar empreendimento relacionado com a derivação ou a utilização de recursos hídricos, superficiais ou subterrâneos, que implique alterações no regime, quantidade ou qualidade dos mesmos, sem autorização dos órgãos ou entidades competentes;

$\mathrm{V}$ - perfurar poços para extração de água subterrânea ou operá-los sem a devida autorização (BRASIL, 1997). 
A PNRH prevê outro instrumento fundamental para a gestão, o Plano Nacional de Recursos Hídricos em que são tratadas diversas questões relacionadas às águas subterrâneas e a sua situação no Brasil, principalmente sobre a qualidade destas águas, que são consideradas de boa qualidade, comprovada pelo uso expressivo das águas minerais de mesa (BRASIL, 2006). 0 documento também destaca o comprometimento dos aquíferos por conta das ações antrópicas e como estratégia de gestão, e discute a importância de superar ambiguidades da atual legislação, apontando a questão das águas subterrâneas como parte dos desafios a serem superados, enfatizando a carência de estudos sistemáticos sobre aquíferos em contexto regional.

As águas subterrâneas são também tratadas nos programas e subprogramas do Plano Nacional, conforme apresentado no Quadro 1.

Quadro 1 - Programas do Plano Nacional de Recursos Hídricos e Água Subterrânea

\begin{tabular}{|c|c|c|}
\hline Programa & Subprograma & Ações e metas \\
\hline $\begin{array}{c}\text { Programa I de estudos } \\
\text { estratégicos sobre recursos } \\
\text { hídricos }\end{array}$ & $\begin{array}{l}\text { I.3 Implementação prática de } \\
\text { compromissos internacionais em } \\
\text { bacias transfronteiriças, } \\
\text { desenvolvimento de instrumentos } \\
\text { de gestão e de apoio à decisão, } \\
\text { compartilhados } \\
\text { com países vizinhos }\end{array}$ & $\begin{array}{c}\text {-Importância de apoiar iniciativas } \\
\text { institucionalizadas como o projeto Aquífero } \\
\text { Guarani }\end{array}$ \\
\hline \multirow{2}{*}{$\begin{array}{c}\text { Programa III de } \\
\text { Desenvolvimento e } \\
\text { Implementação } \\
\text { de Instrumentos de Gestão de } \\
\text { Recursos } \\
\text { Hídricos }\end{array}$} & $\begin{array}{l}\text { III.4 Metodologias e sistemas } \\
\text { de outorga de direitos de uso de } \\
\text { recursos } \\
\text { hídricos }\end{array}$ & $\begin{array}{c}\text {-Trata de metodologias específicas para outorga } \\
\text { das águas subterrâneas. Não há uma metodologia } \\
\text { específica de análise consolidada para todas as } \\
\text { entidades outorgantes estaduais. }\end{array}$ \\
\hline & $\begin{array}{l}\text { III.8 Sistema Nacional de } \\
\text { Informações } \\
\text { sobre Recursos Hídricos }\end{array}$ & $\begin{array}{l}\text {-O Plano deverá conter informações sobre as } \\
\text { províncias hidrogeológicas, como: base geológica, } \\
\text { identificação de aquíferos e suas características, } \\
\text { atividades de produção e consumo, uso e } \\
\text { ocupação do solo, fontes de poluição pontuais e } \\
\text { difusas, além de risco de vulnerabilidade e } \\
\text { susceptibilidade à contaminação. }\end{array}$ \\
\hline $\begin{array}{l}\text { Programa VI de Programa de } \\
\text { Usos Múltiplos e } \\
\text { Gestão Integrada de } \\
\text { Recursos Hídricos }\end{array}$ & $\begin{array}{c}\text { VI.2 } \\
\text { de Gestão da oferta, ampliação, } \\
\text { racionalização e reuso das } \\
\text { disponibilidades } \\
\text { hídricas }\end{array}$ & $\begin{array}{c}\text {-refere-se à indução de recarga natural e artificial } \\
\text { de aquíferos, sistemas de armazenamento e } \\
\text { distribuição de águas subterrâneas, proteção de } \\
\text { áreas de recarga }\end{array}$ \\
\hline
\end{tabular}

Elaborado por Autores, 2017. Fonte: adaptado de BRASIL (2006)

Entre as macrodiretrizes do Plano Nacional está a necessidade de conservação de aquíferos estratégicos, especialmente o Aquífero Guarani (BRASIL, 2006). Nesse sentido, no ano de 2010, Argentina, Paraguai, Uruguai e Brasil assinaram o Acordo sobre o Aquífero Guarani, visando o estabelecimento de princípios para a gestão compartilhada do manancial. No entanto, segundo Santos (2015), o documento pouco se dedica à proteção ambiental do Aquífero Guarani, e muito mais a dizer 
quem são os donos e como eles podem dispor da água. Além disso, o Paraguai ainda não havia ratificado 0 acordo até a redação do presente estudo.

O Plano também apresenta programas regionais de recursos hídricos, em que a água subterrânea passa a ter um programa próprio de gestão, o Programa VIII - Programa Nacional de Águas Subterrâneas (PNAS), que possui três Subprogramas: (I) Ampliação do Conhecimento Hidrogeológico Básico; (II) Desenvolvimento dos Aspectos Institucionais e Legais; (III) Capacitação, Comunicação e Mobilização Social.

\section{A GESTÃO DAS ÁGUAS NAS UGRHIs 04 e 13 E AS ÁREAS DE AFLORAMENTO DO SAG}

As UGRHIs 04 Pardo e 13 Tietê-Jacaré se destacam na área de afloramento do SAG, pois como já apresentado, possuem grande parte de seu território nesta área, utilizam a água subterrânea para abastecimento e possuem a maior incidência de subáreas de proteção especial, que são áreas que estão condicionadas a critérios que devem compatibilizar a ocupação e uso com a proteção das áreas vulneráveis e manutenção da recarga natural do SAG (SÃO PAULO, 2011). Diante de tais aspectos relevantes é imprescindível que se faça uma gestão adequada destas UGRHIs em relação à área de afloramento do SAG.

\subsection{UGRHI 04- Pardo}

A Bacia Hidrográfica do Pardo - UGRHI 04 - integra 27 municípios, dos quais 50\% são abastecidos pelo Aquífero Guarani. Uma área significativa da Bacia corresponde a áreas de recarga do aquífero, presente em 14 municípios (CAMPANHÃO; FONTES; SOUZA; 2014; CPTI, 2008a), conforme mostra a Figura 2. Dentre os municípios que estão na área de afloramento do SAG destacam-se Altinópolis, Santo Antônio da Alegria, Serrana, Serra Azul, Santa Cruz da Esperança, Cássia dos Coqueiros, São Simão. Estes municípios possuem 100\% do seu território na área de afloramento e são considerados de pequeno porte, ou seja, possuem população inferior a 50 mil habitantes (SÃO PAULO, 2011).

O município de Ribeirão Preto, apesar de seu território ocupar apenas $36 \%$ da área de afloramento, é um grande destaque nesta UGRHI, pois, além de ser um município de grande porte, 100\% de seu abastecimento público provém do SAG (SÃO PAULO, 2011). 
Figura 2 - Mapa da UGRHI 04 com destaque para os municípios que estão na área de afloramento do SAG

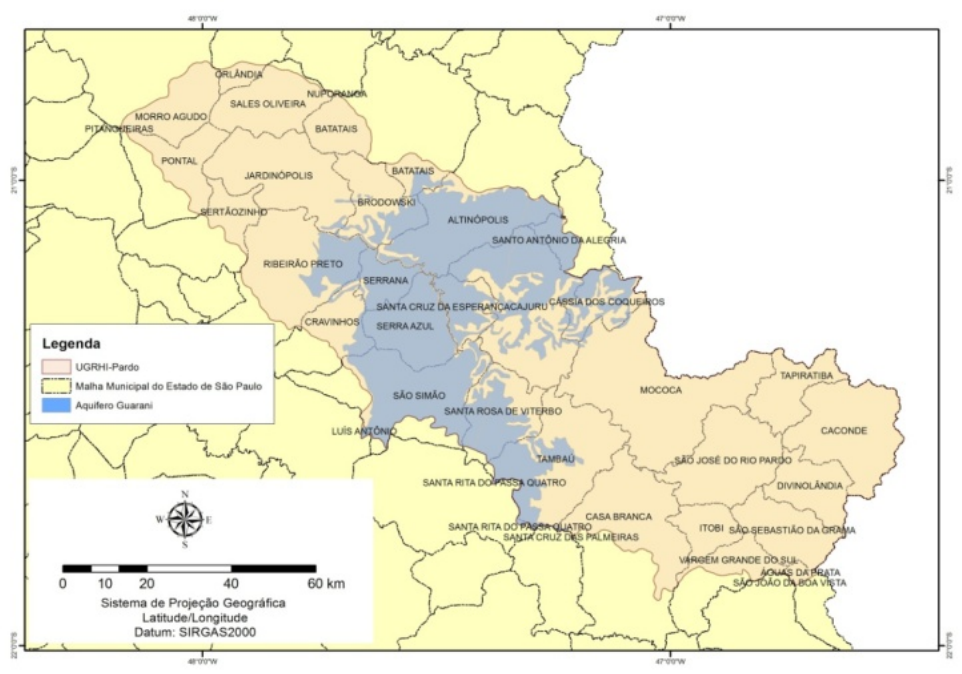

Fonte: Elaborado pelos autores, 2017.

Com relação às atividades econômicas predominantes nestes municípios, que indicam os tipos de uso e prováveis fontes de poluição dos mananciais, tem-se a seguinte distribuição (SÃO PAULO, 2011): Atividades agropecuárias (Altinópolis, Santa Cruz da Esperança e Serra Azul); Agroterciários (Cássia dos Coqueiros e São Simão); Agroindústrias: (Serrana); Indústrias complexas (Ribeirão Preto).

Então, a principal atividade econômica dos municípios que possuem $100 \%$ do seu território nas áreas de afloramento do SAG são atividades agropecuárias, que influem diretamente nas águas subterrâneas. Tanto as atividades agropecuárias, como as atividades industriais praticadas em área de afloramento e recarga do SAG ferem o Decreto $n^{\circ} 32.955$ que trata das Áreas de Proteção Máxima, sendo, portanto, necessário, estudos rigorosos nos Planos de Bacia e o avanço da criação da APRN-SAG por conta destas considerações.

Conforme análise do último Plano de Bacia desta UGRHI, datado de 2009, pode- se constatar que o Aquífero Guarani tem extrema relevância no contexto da gestão. As áreas de afloramento do SAG são classificadas como áreas especiais, e que necessitam de um zoneamento de uso e ocupação específicos, que leve em consideração sua fragilidade.

Um ponto importante levantado no Plano, diz respeito à adequação da realidade dos municípios à Lei de Proteção dos Mananciais, como cenário desejável para o período de 2016 a 2019, o que indica a preocupação com a criação da APRM-SAG, que ainda não está instituída, inclusive por não aparecer no Plano. $O$ documento também faz menção à carência de políticas públicas voltadas para o uso sustentável das águas subterrâneas. 
É recorrente no Plano a necessidade de estudos sobre águas subterrâneas, sobre 0 Aquífero Guarani e a criação de programas de monitoramento da gestão destas águas, principalmente com relação ao cadastro de usuários. $O$ documento propõe a criação de consórcios e demais organizações com vistas a gestão das áreas do Aquífero Guarani

O outro documento analisado foi o Relatório de Situação dos Recursos Hídricos da Bacia 2015, ano-base 2014. Segundo este documento, a disponibilidade hídrica natural per capita da Bacia foi reduzida no período analisado e tende a se tornar cada vez menor. Dentre os municípios que apresentam as menores disponibilidades hídricas estão Ribeirão Preto e Serrana. Esses mesmos municípios estão em situação crítica quanto à explotação de água subterrânea, já que a explotação é maior que 100\% das reservas explotáveis (449\% em Ribeirão Preto) (CBH PARDO, 2015). Já em relação à qualidade das águas subterrâneas, os parâmetros em desconformidade na Bacia estiveram relacionados, principalmente, ao tipo de solo da região.

De acordo com o Relatório, as principais realizações efetuadas na UGRHI, no período de 2013 a 2014, em relação à conservação das águas subterrâneas, foram a redefinição de critérios técnicos para a autorização de perfuração de poços tubulares profundos no município de Ribeirão Preto, e apoio ao conteúdo do projeto de lei de revisão de Plano Diretor do Município de Ribeirão Preto no que concerne à proteção da área de recarga do aquífero Guarani (CBHPARDO, 2015).

Em relação às orientações para a gestão, foi indicado 0 incentivo a programas de pesquisa de recarga de aquíferos; a necessidade de definição de um plano de monitoramento com a integração dos aspectos quantitativos e qualitativos que levem em consideração as inter-relações entre as águas superficiais e subterrâneas; a pesquisa da causa e acompanhamento dos poços que apresentaram desconformidades; a difusão de boas práticas de proteção dos poços profundos (CBH PARDO, 2015).

\subsection{UGRHI 13- Tietê Jacaré}

A Bacia Hidrográfica do Tietê/Jacaré, UGHRI 13, é composta por 34 municípios localizados na região central do estado de São Paulo e que estão relacionados, principalmente, à agroindústria, além de outros setores industriais (CPTI, 2008b). A área de afloramento do SAG corresponde a 39,70\% da área total da UGRHI-13 (SÃO PAULO, 2011), conforme Figura 3, sendo, portanto, uma área significativa que merece atenção e cuidado por parte da comunidade em geral e, especialmente, dos gestores públicos. 
Figura 3 - Mapa da UGRHI 13 com destaque para os Municípios que estão na área de afloramento do SAG

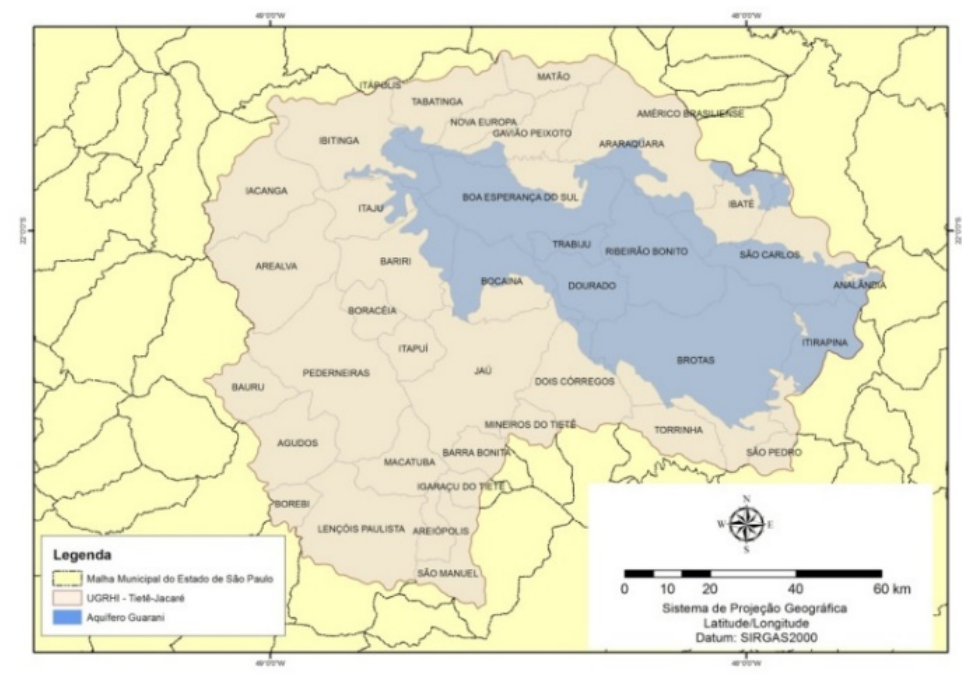

Elaborado pelos autores, 2017.

Segundo o PERH, essa UGRHI está dentre as que apresentaram as menores disponibilidades per capita de água subterrânea do Estado, medidas no ano de 2007 e 2010. (SÃO PAULO, 2013), outro fator que coloca a UGRHI em estado de atenção.

Dentre os municípios que estão na área de afloramento, destacam-se: Trabiju, Ribeirão Bonito, Dourado e Analândia, por possuírem $100 \%$ do seu território nessa área (SÃO PAULO, IPT, 2011), sendo todos municípios de pequeno porte. Os municípios de São Carlos e Araraquara possuem, respectivamente, $88 \%$ e $45 \%$ do seu território localizado na área de afloramento. Apesar disso, apresentam destaque na bacia, pois são os municípios de grande porte populacional e, portanto, possuem grande demanda por água subterrânea utilizando as águas do SAG para $50 \%$ do seu abastecimento público (IPT, 2011).

Com relação às atividades econômicas desenvolvidas nos municípios citados, é possível observar a seguinte distribuição: Agropecuários (Ribeirão Bonito, Trabiju e Dourado) e Indústria complexa (São Carlos e Araraquara).

De forma geral, o Plano de Bacia desta UGRHI datado de 2009 aponta para a necessidade de estudos mais aprofundados sobre o SAG, com vistas ao abastecimento público e para a área de afloramento, sobretudo que indiquem a disponibilidade das águas subterrâneas e que considerem a vulnerabilidade à poluição destas águas. Outro ponto importante do documento é referente a divulgação da Lei de Proteção de Mananciais para toda a UGRHI. Ademais, o Plano prevê para água subterrânea e para o Aquífero Guarani algumas ações e metas sobre o sistema de informações e projetos, e propõe como meta a criação de consórcio de CBHs e demais organizações, com vistas à gestão, sobretudo das áreas do SAG. 
O Relatório de Situação da Bacia do Tietê-Jacaré de 2015 (ano base 2014) destaca a tendência à redução da disponibilidade hídrica per capita na UGRHI devido ao crescimento populacional, impactando principalmente nas águas subterrâneas, que abastecem $69 \%$ da demanda urbana. $O$ documento ressalta, ainda, que a exploração de água subterrânea já alcançou níveis críticos na Bacia Hidrográfica, e que os municípios que apresentam as piores situações são Bauru, Araraquara e Gavião Peixoto, onde a explotação superou $100 \%$ da reserva explotável. Além disso, nove municípios da Bacia apresentam áreas com restrição e deveriam apresentar diretrizes específicas de gestão.

Em relação às orientações para a gestão, foi indicada a elaboração de estudos referentes ao diagnóstico da rede de monitoramento de água subterrânea da UGRHI, tanto em relação ao de nível de água quanto aos parâmetros indicadores de qualidade; elaboração do planejamento do uso da água subterrânea a curto e longo prazo; estabelecimento de áreas de restrição e controle da captação e uso das águas subterrâneas; identificação e proteção das áreas de recarga dos aquíferos, atentando-se para a ocupação do solo nessas áreas; aumento do número de poços de monitoramento, bem como 0 aumento da frequência de monitoramento (CBH-TJ, 2015).

Conforme indicado no Relatório de Situação da Bacia, a principal realização ocorrida no período de 2013 a 2014, referente à conservação das águas subterrâneas, foi uma moção expressando preocupação em relação à exploração de águas subterrâneas na Bacia do Tietê - Jacaré (CBH-TJ, 2015).

\section{CONCLUSÕES}

Ocorreram diversos avanços na gestão das águas subterrâneas desde o Código das Águas em 1934, que consideravam estas águas de domínio privado. Todavia, quando estas águas passaram a pertencer à União, com responsabilidade de legislação Estadual, os esforços para a gestão se concentraram nas outorgas, cobranças e penalidades para o mau uso, tanto na PERH quanto na PNRH. Deste modo, conforme estudos e pesquisas realizados para este trabalho pode-se verificar que as águas subterrâneas ainda são tratadas nas PERH e PNRH de forma superficial, com interesses direcionados às questões econômicas setoriais.

Uma inovação trazida pela PERH é a possível atribuição pelo Estado da responsabilidade da gestão destas águas aos municípios quando os interesses forem exclusivamente locais. Por um lado, tal atribuição descentraliza a gestão e obriga os municípios, que possuem em seus territórios, áreas importantes para a gestão das águas subterrâneas se articularem em interesses coletivos. Por outro, a lei pode abrir uma brecha para a gestão ineficiente destas áreas caso os municípios não 
estejam politicamente e ou tecnicamente preparados para receber a responsabilidade que vem com a gestão descentralizada em promover tal articulação ou mobilização de interesses coletivos.

Segundo Cordeiro de Souza (2012), embora os estados tenham a competência para legislar e gerir sobre as águas subterrâneas, cabe à esfera municipal o adequado ordenamento do território no sentido da ocupação restrita das áreas vulneráveis de aquíferos para a proteção dos mananciais subterrâneos. Compreende-se que o zoneamento ambiental adequado do território para a conservação das águas subterrâneas deve ser contemplado no Plano Diretor dos municípios, especialmente daqueles que possuem parte significativa de sua extensão localizada em áreas de afloramento. Assim, o zoneamento ambiental é um instrumento estratégico que pode representar a diferença entre continuarmos ou não dispondo desse manancial para as futuras gerações (SOUZA, 2012).

Ainda não existe uma legislação nacional específica para águas subterrâneas e a unidade de gerenciamento que é adotada para a gestão das águas é a Bacia Hidrográfica. Então, é possível aferir que a gestão integrada dos recursos hídricos para além da gestão, também apresenta problema conceitual, já que os aquíferos não possuem a mesma delimitação territorial das bacias hidrográficas.

Rebouças (2002), por exemplo, atenta para o fato de que diversos empreendimentos hídricos para recarga artificial de aquífero dependem de uma integração da gestão destas águas subterrâneas com as águas das bacias hidrográficas, sobretudo porque tais obras irão utilizar águas superficiais.

As ações e estratégias para a gestão dos recursos hídricos são definidas nos Planos de Recursos Hídricos, que por sua vez são instrumentos elaborados por bacia hidrográfica de domínio federal ou estadual, por Estado e para o País, desenvolvido, portanto em três níveis: I - Nacional Plano Nacional de Recursos Hídricos; II - Estadual - Planos de Recursos Hídricos dos Estados; III Bacia Hidrográfica - Planos de Recursos Hídricos de Bacias Hidrográficas.

Os Planos Estadual e Nacional de Recursos Hídricos, que são importantes instrumentos de gestão, apesar de abordarem a questão da água subterrânea, o fazem ainda de modo muito generalista e secundário, pois apenas fornecem os diagnósticos gerais destas águas e algumas diretrizes e programas de gestão, que estabelecem metas de curto, médio e longo prazo. Os Planos propõem programas para a gestão das águas subterrâneas, que incluem o levantamento e a difusão de informações sobre estas águas e o estabelecimento de normativas e legislações específicas.

Foi possível constatar que o estado de São Paulo possui uma lei estadual para disciplinar o uso e dar as diretrizes para as águas subterrâneas, estabelecendo áreas de proteção e recuperação, e que coloca as áreas de recarga de aquíferos como altamente vulneráveis, portanto são áreas de proteção máxima. Por conta da importância destas áreas, a lei de Proteção de Mananciais do estado 
de São Paulo define as prioridades e diretrizes para a criação de APRM, que são incompatíveis com o uso agrícola presente em tais áreas. Entre elas está a APRM-SAG que, apesar de alguns esforços do estado, ainda não foi estabelecida legalmente. Tal situação impede o avanço de uma gestão adequada das águas subterrâneas no SAG, abrindo brechas para o descontrole da poluição, problemas de recarga, falta de metodologias e instrumentos apropriados, dentre outros.

Com relação às UGRHIs 04 Pardo e 13 Tietê - Jacaré, esperava-se que os Planos de Bacia e os Relatórios de Situação contemplassem as APRMs, ou ao menos valorizassem a gestão nas áreas de afloramento do SAG, principalmente nos municípios que possuem seu território localizado totalmente dentro da área de recarga. Além disso, seria relevante a abordagem das APRMs nos Planos, pois nestes municípios predomina a classe agrícola de uso e ocupação, o que indica também a importância da fiscalização constante e das iniciativas municipais para a promoção de legislações referentes a APRM-SAG, por conta da frequência da utilização de fertilizantes e agrotóxicos e da compactação e do solo pelo uso de maquinários pesados.

Esses documentos citam a necessidade de um avanço na quantidade e qualidade dos estudos e identificação das áreas de recarga para contribuir com o zoneamento de uso e ocupação, e indicam a necessidade de divulgação da Lei de Proteção de Mananciais.

A partir da análise destes documentos, foi possível concluir que a gestão integrada dos recursos hídricos - superficiais e subterrâneos - ainda não está ocorrendo, e este é um desafio. Segundo São Paulo (2011), a integração dos Planos Diretores e de Bacia Hidrográfica, com o PDPA e demais instrumentos da gestão municipal e de águas é fundamental. Por isso, novamente é preciso ressaltar que é imprescindível que a legislação para a proteção da APRM-SAG seja implementada, e ainda que, os municípios que estão totalmente inseridos nessa área, ou que possuem um abastecimento elevado por águas subterrâneas, façam uma gestão integrada efetiva, sobretudo por intermédio dos Comitês de Bacia Hidrográfica.

Ensina-nos Cordeiro de Souza (2012) que os municípios, com auxílio do Estado e da União, por ter a função constitucional de ordenar o uso do solo, devem se tornar os protagonistas na proteção das águas subterrâneas. Deste modo, é preciso que os municípios participem ativamente das decisões que serão tomadas para a gestão destas áreas, propondo dentro dos colegiados responsáveis, legislações específicas e ações cabíveis, efetivando também, com isso, a gestão descentralizada dos recursos hídricos. 


\section{REFERÊNCIAS}

ALBUQUERQUE FILHO, J.L; NICOLAU, M; Moreira, D; CARVALHO, A. Estudo da recarga na área de afloramento do Sistema Aquífero Guarani na unidade de gerenciamento de recursos hídricos do Tietê/Jacaré, região central do estado de São Paulo: Resultados Preliminares. In: XVI Congresso brasileiro de águas subterrâneas e XVII Encontro nacional de perfuradores de poços, 2010, São Luís. São Luís: Abas, 2010. p. 1-13.

ABAS. Associação Brasileira de Águas subterrâneas. Águas subterrâneas: o que são. Volume Educação. Disponível em: https://www.abas.org/aguas-subterraneas-o-que-sao/. Acesso: 11 nov. 2017.

BRASIL. Presidência da República. LEI No 9.433, DE 8 DE JANEIRO DE 1997. Institui a Política Nacional de Recursos Hídricos, cria o Sistema Nacional de Gerenciamento de Recursos Hídricos. Casa Civil. Subchefia para Assuntos Jurídicos. Disponivel em: http://www.planalto.gov.br/ccivil_03/LEIS/L9433.htm. Acesso em: 14 out. 2017.

BRASIL. Ministério do Meio Ambiente. Plano Nacional de Recursos Hídricos. Programas nacionais e metas: Volume 4 / MMA/ SRH. Brasilia: MMA, 2006.

BRASIL. Ministério do Meio Ambiente. Secretaria de Recursos Hídricos e Ambiente Urbano. Águas subterrâneas. Um recurso a ser conhecido e protegido. Brasília: MMA/SRH, 2007.

BRASIL. Ministério do Meio Ambiente. Águas subterrâneas no Brasil. Disponível em: https://www.mma.gov.br/agua/recursos-

hidricos/interaguas/itemlist/category/index.php?option=com_k2\&view=item\&id=418\&ltemid=473.

Acesso: 11 nov. 2017.

CAMPANHÃO, L.M.B.; FONTES, A.T.; SOUZA, M.P.de. Proposta de criação de espaços territoriais a serem especialmente protegidos em uma zona de recarga do Sistema Aquífero Guarani no município de Ribeirão Preto, SP. Desenvolvimento e Meio Ambiente, Curitiba, v.29, p. 93-112, 2014.

CBH-P, COMITÊ DA BACIA HIDROGRÁFICA DO RIO PARDO. Relatório de situação dos recursos hídricos da bacia hidrográfica 2015 (ano base 2014). Comitê da Bacia Hidrográfica do Pardo; Grupo de Trabalho Permanente do Relatório Anual de Situação dos Recursos Hídricos e Plano de Bacia UGRHI-4 Pardo - Ribeirão Preto, 2015, 96 p.

CBH- TJ, COMITÊ DA BACIA HIDROGRÁFICA DO TIETÊ-JACARÉ. Relatório de situação dos recursos hídricos da bacia hidrográfica 2015 (ano base 2014). Comitê da Bacia Hidrográfica do Tietê - Jacaré. 2015, 130 p.

CPTI. Plano de Bacia da Unidade de Gerenciamento de Recursos Hídricos do Pardo (UGRHI-4): Revisão para atendimento à Deliberação $\mathrm{CRH}$ 62. Cooperativa de serviços e pesquisas tecnológicas e industriais. São Paulo: Cpti, 2008a. 363 p.

CPTI. Plano de Bacia da Unidade de Gerenciamento de Recursos Hídricos do Tietê/Jacaré (UGRHI13): Revisão para atendimento à Deliberação $\mathrm{CRH}$ 62. Cooperativa de serviços e pesquisas tecnológicas e industriais. São Paulo: Cpti, 2008b. 232 p. 
DAEE. Mapa de águas subterrâneas do Estado de São Paulo: escala 1:1. 000.000: nota explicativa / [coordenação geral Gerôncio Rocha]. - São Paulo: DAEE Departamento de Águas e Energia Elétrica: Instituto Geológico: IPT Instituto de Pesquisas Tecnológicas do Estado de São Paulo: CPRM Serviço Geológico do Brasil, 2005.

FIESP, Federação das Indústrias do Estado de São Paulo. Orientações para a utilização de águas subterrâneas no estado de São Paulo. ABAS. DH. 2005.

HIRATA, R.; ZOBY, J.L.G.; OLIVEIRA, F.R.de. Água Subterrânea: reserva estratégica ou emergencial. In: BICUDO, C.E.de.M.; TUNDISI, J.G.; SCHEUENSTUHL, M.C.B. Águas do Brasil: análises estratégicas. São Paulo: Instituto de Botânica, 2010. p.149-161.

IRITANI, M.A.; EZAKI, S. As águas subterrâneas do Estado de São Paulo. Série: Cadernos de Educação Ambiental. São Paulo: Secretaria de Estado do Meio Ambiente - SMA, 2012. 104p.

OEA. ORGANIZAÇÃO DOS ESTADOS AMERICANOS. Aquífero Guarani: Programa estratégico de ação. Edição Bilíngue-Brasil, Argentina, Paraguai, Uruguai: OEA, 2009. 424 p.

RABELO, J.L. Estudo da recarga do Aquífero Guarani no sistema Jacaré-Tietê.2006. 200 f. Tese (Doutorado) - Curso de Engenharia Civil, Hidráulica e Saneamento, Escola de Engenharia de São Carlos - Universidade de São Paulo, São Carlos, 2006.

REBOUÇAS, A.C. A Política Nacional de Recursos Hídricos e as Águas Subterrâneas. Revista de Águas subterrâneas $\mathrm{n}$ 16. maio:2002

REBOUÇAS, A.C. Águas subterrâneas. In: REBOUÇAS, A.C.; BRAGA, B.; TUNDIZI, J.G. (org.). Águas Doces no Brasil: Capital ecológico, uso e conservação. 3. ed. São Paulo: Escrituras, 2006. p. 111-144.

RAMOS VOSGERAU, D. S.; ROMANOWSKI, J. P. Estudos de revisão: implicações conceituais e metodológicas. Revista Diálogo Educacional, v. 14, n. 41, 2014.

SANTOS, C.L.S. Aquífero Guarani: Atuação do Brasil na Negociação do Acordo. 2015. 193 p. Dissertação (Mestrado). - Programa de Pós-Graduação em Ciência Ambiental, Instituto de Energia e Ambiente, Universidade de São Paulo, São Paulo, 2015.

SÃO PAULO (Estado). Secretaria do Meio Ambiente. INSTITUTO DE PESQUISAS TECNOLÓGICAS DO ESTADO DE SÃO PAULO (IPT). Subsídios ao Plano de Desenvolvimento e Proteção Ambiental da área de afloramento do Sistema Aquífero Guarani no Estado de São Paulo. CPLA: São Paulo, 2011.

SÃO PAULO (Estado). LEI N. 6.134, DE 2 DE JUNHO DE 1988. Dispõe sobre a preservação dos depósitos naturais de águas subterrâneas do Estado de São Paulo e dá outras providências. Assembleia Legislativa do Estado. Disponível em: https://www.al.sp.gov.br/repositorio/legislacao/lei/1988/lei-6134-02.06.1988.html. Acesso em: 11 nov. 2017.

SÃO PAULO (Estado). LEI No 7.663, DE 30 DE DEZEMBRO DE 1991a. Estabelece normas de orientação à Política Estadual de Recursos Hídricos bem como ao Sistema Integrado de Gerenciamento de Recursos Hídricos. 1991. Assembleia Legislativa do Estado. Disponível em 
https://www.al.sp.gov.br/repositorio/legislacao/lei/1991/alteracao-lei-7663-30.12.1991.html. Acesso em: 11 nov. 2017.

SÃO PAULO (Estado). DECRETO N. 32.955, DE 7 DE FEVEREIRO DE 1991b. Regulamenta a Lei $n$. 6.134, de 2 de junho de 1988. Assembleia Legislativa do Estado. Disponível em https://www.al.sp.gov.br/repositorio/legislacao/decreto/1991/decreto-32955-07.02.1991.html. Acesso em: 11 nov. 2017.

SÃO PAULO (Estado). LEI ESTADUAL № 9.866, DE 28 DE NOVEMBRO DE 1997. Dispõe sobre diretrizes e normas para a proteção e recuperação das bacias hidrográficas dos mananciais de interesse regional do Estado de São Paulo e dá outras providências. Assembleia Legislativa do Estado. Disponível em: https://www.al.sp.gov.br/repositorio/legislacao/lei/1997/lei-986628.11.1997.html. Acesso: 11 nov. 2017.

SÃO PAULO. Relatório de qualidade das águas subterrâneas do estado de São Paulo: 2007-2009 [recurso eletrônico] Companhia de Tecnologia de Saneamento Ambiental/ São Paulo: CETESB, 2010. Disponível em: https://cetesb.sp.gov.br/aguas-subterraneas/publicacoes-e-relatorios/. Acesso em: 11 nov. 2017.

SÃO PAULO. Relatório de qualidade das águas subterrâneas do estado de São Paulo:20132015[recurso eletrônico] Companhia de Tecnologia de Saneamento Ambiental / São Paulo: CETESB, 2016. Disponível em: https://cetesb.sp.gov.br/aguas-subterraneas/publicacoes-e-relatorios/. Acesso em: 11 nov. 2017.

SÃO PAULO (Estado). Plano Estadual de Recursos Hídricos (PERH): 2012/2015. Secretaria de Saneamento e Recursos Hídricos. Coordenadoria de Recursos Hídricos. São Paulo: SSRH/CRHi, 2013. $210 p$.

SÃO PAULO (Estado). SECRETARIA ESTADUAL DO MEIO AMBIENTE, 2007. DATAGEO. Disponível em: http://datageo.ambiente.sp.gov.br/app/. Acesso em: 11 nov. 2017.

SENRA, J.B; DOS SANTOS SOUZA, R; BAPTISTA, M. O papel do plano nacional de recursos hídricos na implementação de uma política nacional de águas subterrâneas. ANAIS: XVII Congresso Brasileiro de Águas Subterrâneas e XVIII Encontro Nacional de Perfuradores de Poços. Bonito. MS. 2012. Disponível em: https://aguassubterraneas.abas.org/asubterraneas/article/view/27762. Acesso em: 11 nov. 2017.

SOUZA, L. Cordeiro de. O município como partícipe na proteção das águas subterrâneas no Brasil. Boletín Geológico y Minero, 2012. v. 123, n.3, p.377-388.

VILLAR, P.C. Gestão das águas subterrâneas e o Aquífero Guarani: desafios e avanços. V Encontro Nacional da Anppas.4 a 7 de outubro de 2010. Florianópolis - SC - Brasil, 2010.

VILLAR, P.C. A busca pela governança dos aquíferos transfronteiriços e o caso do Aquífero Guarani.2012. 261 f. Tese (Doutorado) - Curso de Programa de Pós-Graduação em Ciência Ambiental, Universidade de São Paulo, São Paulo, 2012. 